УДК 622.276.53

ОБОСНОВАНИЕ НАПРАВЛЕНИЙ СОВЕРШЕНСТВОВАНИЯ

КЛАПАННЫХ ПАР ПОРШНЕВОГО БУРОВОГО НАСОСА

С ЦЕЛЬЮ ПОВЫШЕНИЯ ИХ НАРАБОТКИ НА ОТКАЗ

И ГЕРМЕТИЧНОСТИ

\title{
SUBSTANTIATION OF IMPROVEMENT DIRECTIONS \\ OF PISTON DRILLING PUMP VALVE PARTS \\ FOR THEIR FAILURE AND TIGHTNESS IMPROVING
}

\author{
М.И. Харисов, Ф.Ш. Забиров \\ Уфимский государственный нефтяной технический университет, \\ г. Уфа, Российская Федерация \\ Marsel I. Kharisov, Ferdinand Sh. Zabirov \\ Ufa State Petroleum Technological University, \\ Ufa, Russian Federation \\ e-mail: marselkharisov2009@yandex.ru
}

Аннотация. Наработка на отказ буровых поршневых насосов лимитируется работоспособностью быстроизнашивающихся деталей и узлов ее гидравлической части. Надежность последней зависит от износостойкости деталей и узлов цилиндропоршневой группы и клапанных пар, основными из которых являются цилиндровые втулки, поршень с сердечником, шток, седло клапана, клапан, гидравлическая коробка, а также уплотнения цилиндровой втулки, клапана, седла, крышек гидравлической коробки. Детали клапанных пар буровых насосов изнашиваются быстрее, чем детали цилиндропоршневых групп. Повышенная интенсивность изнашивания деталей гидравлической части бурового поршневого насоса обусловлена содержанием абразивных частиц в перекачиваемой буровым поршневым на- 
сосом промывочной жидкости, действием высоких контактных напряжений на рабочих поверхностях основных деталей и узлов гидравлической части бурового насоса, циклическим и ударным характером действия нагрузок на рабочих поверхностях вышеуказанных деталей и узлов, а также недостаточной износостойкостью всех подвижных и неподвижных сопрягаемых поверхностей, в частности зеркала цилиндра, уплотнения поршня, тарели клапана и седла клапана. Для обеспечения восстановления работоспособности гидравлической части буровых поршневых насосов требуется периодически временно выводить из эксплуатации, что обусловливает отвлечение буровой бригады от проведения работ, непосредственно связанных с бурением скважины. Простои буровой бригады, вызванные необходимостью замены вышедших из строя деталей и узлов гидравлической части бурового поршневого насоса, отрицательно сказываются на экономических показателях строительства скважины. В статье приведены результаты патентных исследований и литературного обзора, касающиеся конструкций и надежности клапанных пар буровых поршневых насосов, а также обоснование направлений дальнейших исследований по повышению их технического уровня.

Abstract. The mean-time between failures of piston-driven drilling pumps is limited by the performance of high-wear parts and components of its hydraulic part. The reliability of the latter depends on the wear resistance of parts and assemblies of the cylinder-piston group and valve pairs, the main ones are cylinder bushings, piston with core, rod, valve seat, seat, hydraulic box, and seals of cylinder sleeve, valve, seat, hydraulic box covers. Details of valve pairs of mud pumps wear out faster than parts of cylinder-piston groups. Increased wear rate of parts of the hydraulic part of a piston pump due to the content of abrasive particles in the flushing fluid pumped by the piston pump, the action of high contact stresses on the working surfaces of the main parts and assemblies of the hydraulic part of the mud pump, cyclic and shock action of the loads on the working surfaces of the above parts and assemblies, as well as insufficient wear re- 
sistance of all moving and stationary interacting surfaces, in particular, cylinder mirrors, piston seals of a plate valve and the valve seat. To ensure the recovery of the hydraulic part of the piston drilling pumps, they need to be periodically temporarily taken out of service, which leads to the diversion of the drilling crew from work directly related to the well drilling. The downtime of the drilling crew, caused by the need to replace the defective parts and components of the hydraulic part of the piston pump, adversely affect the economic performance of the well construction. The article presents the results the study of patents and articles review concerning the design and reliability of valve pairs of piston of the slush piston pumps, as well as the substantiation of future research directions for their engineering level improving.

Ключевые слова: буровой поршневой насос, клапанная пара, клапан, седло клапана, тарель клапана, уплотнение клапана

Key words: piston pump, valve pair, valve, valve seat, valve plate, valve seal

Гидравлическая часть современных конструкций отечественных и зарубежных буровых поршневых насосов включает в свой состав гидравлические коробки, клапанные пары, цилиндропоршневые группы, уплотнения штоков поршней и крышек клапанных пар, цилиндровые втулки и крышки клапанных пар цилиндровой группы. Несмотря на совершенствование конструкции гидравлической части буровых поршневых насосов и технологии их изготовления, показатели ее надежности не в полной мере соответствуют предъявляемым требованиям, в первую очередь, по наработке на отказ. В таблице 1 приведены результаты статистической обработки информации о наработке деталей гидравлической части буровых насосов, полученные в ранее выполненных работах по исследованию буровых поршневых насосов [1-3]. 
Таблица 1 - Результаты статистической обработки информации о наработке деталей буровых насосов

\begin{tabular}{|l|l|c|c|}
\hline \multirow{2}{*}{\multicolumn{1}{|c|}{ Деталь }} & \multicolumn{2}{|c|}{ Закон распределения } & \multicolumn{2}{|c|}{$\begin{array}{c}\text { Статистический параметр } \\
\text { распределения }\end{array}$} \\
\cline { 3 - 4 } & & $\begin{array}{c}\text { Наработка } \\
\text { до отказа, ч }\end{array}$ & $\begin{array}{c}\text { Коэффициент } \\
\text { вариации }\end{array}$ \\
\hline Поршень & Экспоненциальный & 98 & 0,83 \\
\hline $\begin{array}{l}\text { Цилиндровые } \\
\text { втулки }\end{array}$ & Вейбулла & 204 & 0,52 \\
\hline Штоки & $\begin{array}{l}\text { Логарифмически- } \\
\text { нормальный }\end{array}$ & 106 & 0,48 \\
\hline Клапаны & Экспоненциальный & 73 & 0,77 \\
\hline
\end{tabular}

Значения коэффициента вариации экспоненциального закона распределения наработки на отказ поршней и клапанов буровых насосов, равные 0,83 и 0,77 соответственно, свидетельствуют о высокой вероятности внезапного выхода из строя этих деталей.

Широкий диапазон изменений значений среднеквадратичного отклонения наработки на отказ поршней и клапанов буровых насосов также свидетельствует о том, что долговечность и износостойкость этих деталей зависят от влияния большого числа различных факторов. Аналогичные выводы были получены в результате исследований и других авторов [4].

Например, в работе [5] отмечено почти двукратное сокращение наработки на отказ деталей гидравлической части буровых насосов при бурении скважин в интервале 4000-5000 м по сравнению с бурением скважины в интервале 1000-2000 м. Следствием этого является соответствующее увеличение количества расходуемых деталей и узлов, в том числе клапанных пар, используемых для восстановления работоспособности буровых поршневых насосов (рисунок 1). Как видно из рисунка 1, клапанная пара бурового поршневого насоса является самой его быстро изнашиваемым узлом. По данным, приведенным в $[6,7]$, можно заметить, что клапанные пары изнашиваются быстрее, чем остальные детали гидравлической части бурового поршневого насоса.

Из вышеизложенного следует, что надежность деталей гидравлической части бурового поршневого насоса в значительной степени зависит от из- 
носостойкости взаимно контактирующих поверхностей и уплотнительных элементов поршня и клапанной пары. Например, средняя наработка на отказ клапанов буровых поршневых насосов, нагнетающих промывочную жидкость под давлением 16-18 МПа, не превышает 100 ч [5].

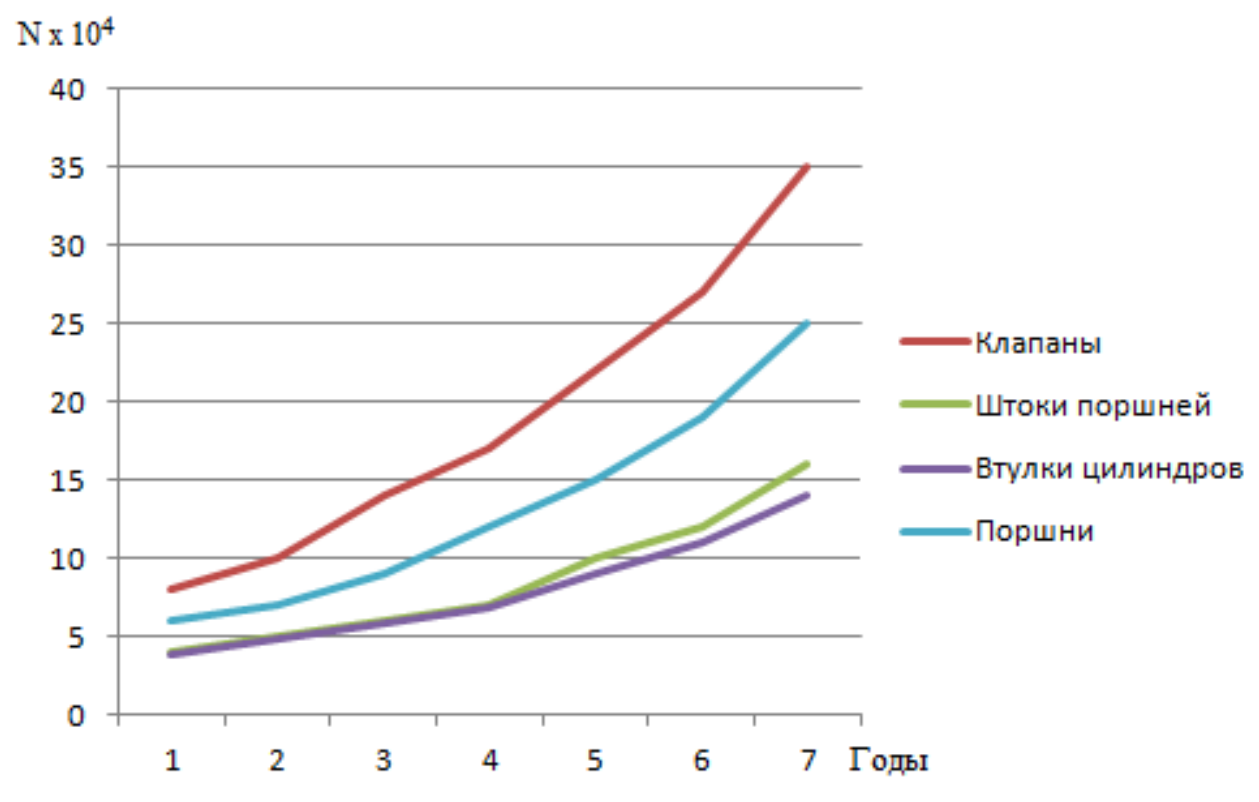

1 - клапаны, 2 - поршни, 3 - штоки поршней, 4 - втулки цилиндров

Рисунок 1. Соотношения количества расходуемых деталей по их видам

Замена изношенных узлов и деталей бурового поршневого насоса в процессе бурения скважины требует значительных материальных и трудовых затрат, применения тяжелого ручного труда в весьма неблагоприятных климатических условиях, а также временного вывода бурового насоса из эксплуатации $[1,5]$.

В процессе бурения скважины клапаны бурового поршневого насоса, как правило, заменяются на новые чаще, по сравнению с другими деталями гидравлической части насоса. Изучение характера повреждений отработанных клапанов буровых поршневых насосов, проведенного в процессе проведения ремонта последних на базах производственного обслуживания ряда буровых компаний $[1,6]$, показало, что причинами их выхода из строя 
являются ведущие виды износа, а также различные повреждения их рабочих поверхностей (таблица 2).

Таблица 2. Сведения наработки клапанов буровых насосов

\begin{tabular}{|c|c|c|c|c|c|}
\hline $\begin{array}{c}\text { Тип } \\
\text { насоса }\end{array}$ & $\begin{array}{c}\text { Марка } \\
\text { клапана }\end{array}$ & $\begin{array}{l}\text { Диаметр } \\
\text { клапана }\end{array}$ & $\begin{array}{c}\text { Характер } \\
\text { повреждений } \\
\text { поверхности дета- } \\
\text { ли }\end{array}$ & $\begin{array}{c}\text { Ведущий вид из- } \\
\text { носа детали }\end{array}$ & $\begin{array}{c}\text { Наименование } \\
\text { буровой } \\
\text { компании }\end{array}$ \\
\hline НБТ-600 & НБТ600 & 160,9 & $\begin{array}{l}\text { Царапины и глу- } \\
\text { бокие риски на } \\
\text { рабочих поверх- } \\
\text { ностях стальных } \\
\text { деталей }\end{array}$ & Абразивный & $\begin{array}{l}\text { Азнакаевское } \\
\text { УБР (управле- } \\
\text { ние буровыми } \\
\text { работами) }\end{array}$ \\
\hline НБ-375 & НБ375 & 163,0 & $\begin{array}{l}\text { Лунки, вмятины, } \\
\text { неглубокие тре- } \\
\text { щины, выкраши- } \\
\text { вание, наклеп ра- } \\
\text { бочих поверхно- } \\
\text { стях стальных де- } \\
\text { талей }\end{array}$ & $\begin{array}{l}\text { Ударно- } \\
\text { гидроабразивный }\end{array}$ & $\begin{array}{l}\text { Азнаевское } \\
\text { УБР }\end{array}$ \\
\hline БрН-1 & НБ125 & 163,0 & $\begin{array}{l}\text { Коррозия рабочей } \\
\text { поверхности ме- } \\
\text { таллических дета- } \\
\text { лей }\end{array}$ & $\begin{array}{l}\text { Коррозионно- } \\
\text { механический }\end{array}$ & $\begin{array}{l}\text { Туймазинское } \\
\text { УБР }\end{array}$ \\
\hline $9 \mathrm{~T}$ & НБ125 & 111,0 & $\begin{array}{l}\text { Срезание и сколы } \\
\text { части рабочей по- } \\
\text { верхности детали }\end{array}$ & Механический & $\begin{array}{l}\text { Туймазинское } \\
\text { УБР }\end{array}$ \\
\hline 9 МГр & НБ125 & 111,0 & $\begin{array}{l}\text { Изменение разме- } \\
\text { ров и формы эла- } \\
\text { стичных деталей }\end{array}$ & - & $\begin{array}{l}\text { Туймазинское } \\
\text { УБР }\end{array}$ \\
\hline УНБ-600 & К101Д & 198,5 & $\begin{array}{l}\text { Пластическая де- } \\
\text { формация рабочей } \\
\text { поверхности, на- } \\
\text { личие поверхно- } \\
\text { стных и внутрен- } \\
\text { них трещин, раз- } \\
\text { рыв манжеты }\end{array}$ & Усталостный & $\begin{array}{l}\text { Туймазинское } \\
\text { УБР }\end{array}$ \\
\hline $\begin{array}{l}\text { УНБ-600, } \\
\text { УНБТ 1180L }\end{array}$ & К101Д & 198,5 & $\begin{array}{l}\text { Изменение разме- } \\
\text { ров и формы эла- } \\
\text { стомеров }\end{array}$ & $\begin{array}{l}\text { Усталостный, } \\
\text { пластическая де- } \\
\text { формация }\end{array}$ & $\begin{array}{l}\text { Буровая ком- } \\
\text { пания «Евра- } \\
\text { зия» }\end{array}$ \\
\hline $\begin{array}{l}\text { 3NB-1600 } \\
\text { QF-1300 }\end{array}$ & & 198,5 & $\begin{array}{l}\text { глубокие риски на } \\
\text { рабочей поверх- } \\
\text { ности трения } \\
\text { стальных деталей, }\end{array}$ & Абразивный & $\begin{array}{l}\text { «СГК- } \\
\text { Бурение» }\end{array}$ \\
\hline
\end{tabular}

Например, внутренняя поверхность седел клапанов характеризовалась наличием на ней прямолинейных выбоин, рисок и вмятин, ориентирован- 
ных вдоль ее образующей. Результаты анализа также показали, что негерметичность клапанной пары бурового поршневого насоса, как правило, является следствием неплотной посадки тарели клапана на посадочную поверхность седла клапана, образованием зазора между контактирующими поверхностями при закрытом положении клапана [1].

В целях обоснования направлений для дальнейшего совершенствования конструкций клапанных пар буровых поршневых насосов был проведен литературный обзор и патентных исследований за последние десятилетия по указанной тематике.

В работе [8] приводится техническое решение: посадочное гнездо седла выполнено в форме конуса, переходящего в цүилиндр.

Такое конструктивное решение, по мнению авторов публикации, обеспечивает наименьший взаимный износ рабочих поверхностей седла и тарели клапана. Кроме того, за счет уменьшения высоты конусной части тарели, выполненной в виде конического диска, обеспечивается снижение ударной нагрузки при посадке клапана за счет одновременной ее посадки на торцевую часть нижележащей цилиндрической поверхности.

В работе [4], посвященной виброизоляции клапана бурового насоса, предложено установить между седлом клапана и корпусом бурового насоса эластичный элемент.

Расчеты, приведенные в вышеуказанной работе, показали, что применение эластичного элемента приведет к многократному (в десятки раз) снижению ударных усилий, передаваемых на корпус насоса.

Известен клапан бурового насоса [9], состоящий из седла, тарелки, уnлотняющего кольца, элементов крепления и пружины. Недостатком этой конструкции клапана является то, что уплотнитель дисковой формы, закрепленный на тарели, после многочисленных циклов срабатывания клапана разрушается со стороны элементов крепления в виде локальных вырывов материала эластомера. 
Известен клапан бурового насоса [10], состоящий из седла, тарели, уnлотнителя, привулканизированного к седлу, направляющего элемента и пружинь.

Герметизация этого клапана обеспечивается резиновым уплотнением, наружная поверхность которого выступает относительно внутреннего посадочного конуса седла. Недостатком этой конструкции клапана является износ заостренной части манжеты, который приводит к промыву клапана, то есть к потере герметичности и полному выходу из строя клапанного узла.

В [11] уплотнение клапанной пары осуществляется под действием сил, создаваемых давлением нагнетаемой промывочной жидкости, а также упругих сил, возникающих при обжатии кольца.

В [12] плавающее исполнение тарели клапана относительно штока клапана обеспечивает снижение динамических нагрузок при работе клапанной пары за счет уменьшения перекоса тарели клапана относительно седла и отклонения от соосности.

В [13] введение в конструкцию магнитного элемента позволяет повысить быстродействие клапана - уменьшить время его срабатывания.

В [14] увеличение надежности клапанной пары обеспечивается введением в конструкцию дополнительной тарели на штоке, разгружающей основную тарель.

В [15] повышение долговечности клапана обеспечивается за счет создания повыщенного крутящего момента на тарели и повышения соосности (центровки) клапанной пары.

Это обеспечивается выполнением каналов переменного сечения, увеличивающихся к периферии запорного органа.

В результате этого основная часть нагрузки, возникающей от давления потока промывочной жидкости, распределяется по периферийной части тарели, увеличивая длину плеча действия сил и значение крутящего момента на тарели. 
В [16] повышение износостойкости клапанной пары под воздействием высокоскоростных струй жидкости, содержащих абразивные частицы, обеспечивается за счет размещения на клапане ниже уплотняющей конической поверхности цилиндрического пояска-плунжера высотой 3-5 мм.

В [17] предложена конструкциия клапанной пары повышенного ресурса, предотвращающей преждевременное разрушение уплотнительной манжеты за счет выполнения на седле дополнительного уступа, удерживающего уплотнительное кольцо, препятствующего проникновению твердых абразивных частиц в зазор между тарелью клапана и уплотнительным кольцом.

В тех случаях, когда абразивные частицы попадают в зазор между тарелью клапана и седлом, уплотнительное кольцо обеспечивает перекрытие этого зазора под действием давления жидкости, так как значение ширины уступа седла меньше, чем значение толщины уплотнительного кольца.

В работе [18], посвященной изучению работы клапанных пар, приведена разработанная математическая модель для расчета коэффициента гидравлического сопротивления клапанных пар.

Опираясь на разработанную математическую модель, были получены гидравлические характеристики работы клапанных узлов.

На рисунках 2-5 представлены сравнительные характеристики работы клапанных узлов при одинаковых исходных параметрах.

Анализ рисунков 2-5 свидетельствует о том, что гидравлические характеристики различных типов клапанных пар сильно отличаются друг от друга для одних и тех же условий испытаний. Поэтому эти различия следует учитывать при совершенствовании конструкций тарельчатых клапанов буровых поршневых насосов, так они в значительной степени обусловливают их конструктивные параметры и конструктивные особенности исполнения их отдельных элементов. 


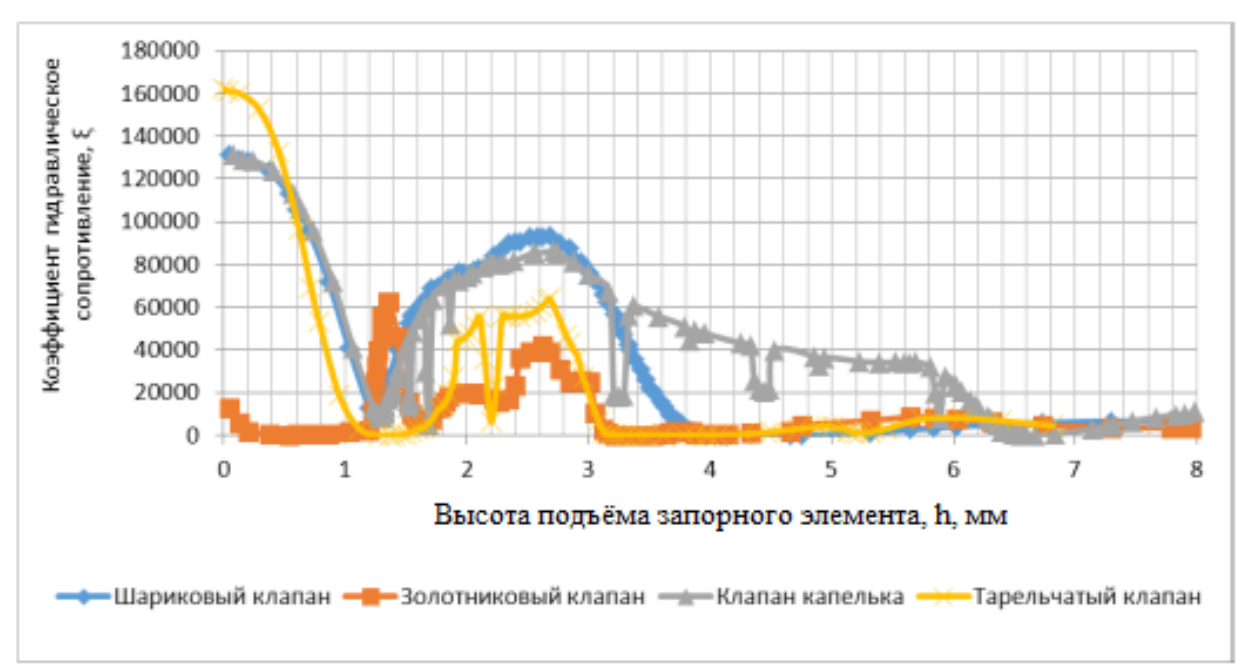

Рисунок 2. График изменения значения коэффициента сопротивления клапанной пары в зависимости от значения высоты подъема (h) запорного элемента

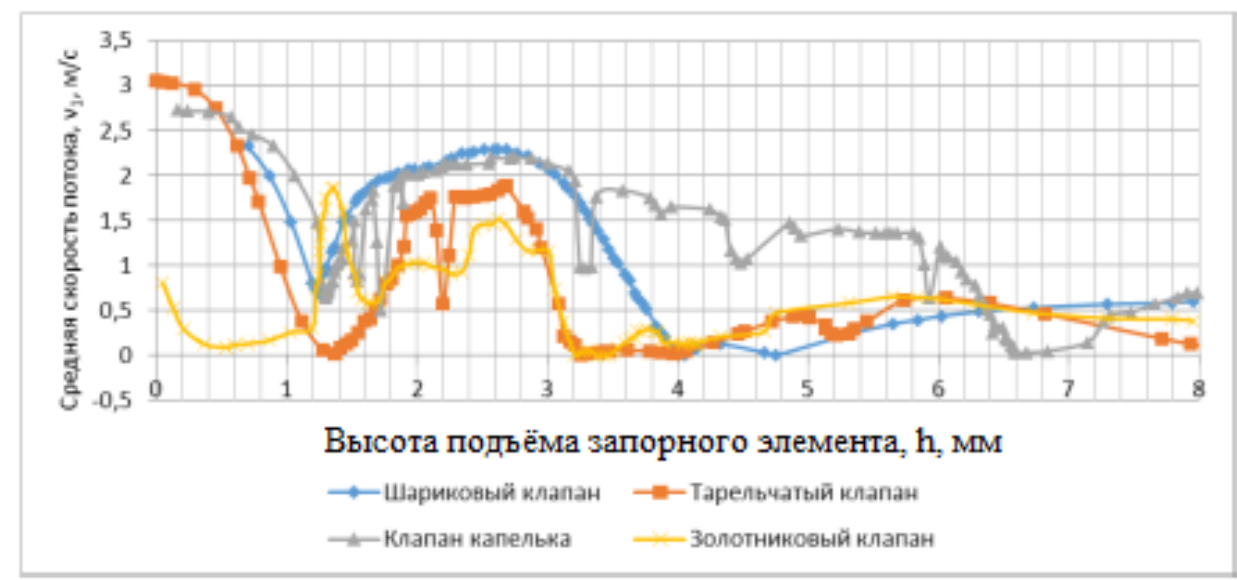

Рисунок 3. График изменения средней скорости v потока жидкости от высоты подъема h запорного элемента клапанной пары

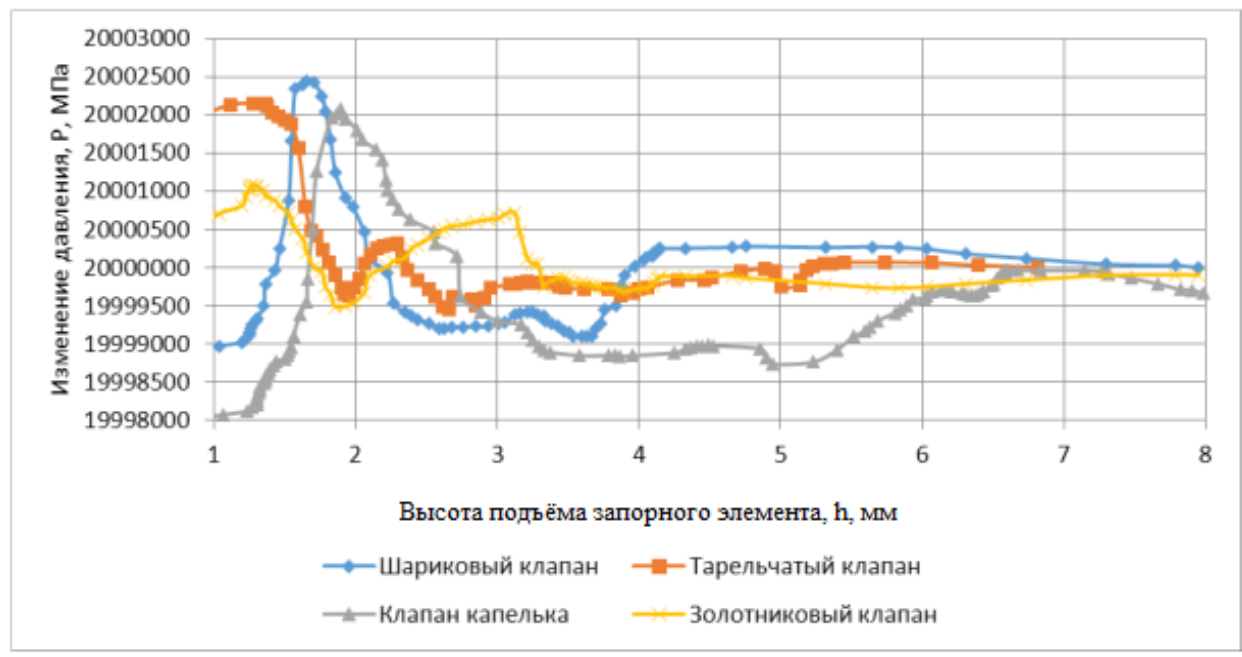

Рисунок 4. График изменения значения давления Р потока жидкости в клапанной паре в зависимости от значения высоты подъема $\mathrm{h}$ его запорного элемента 


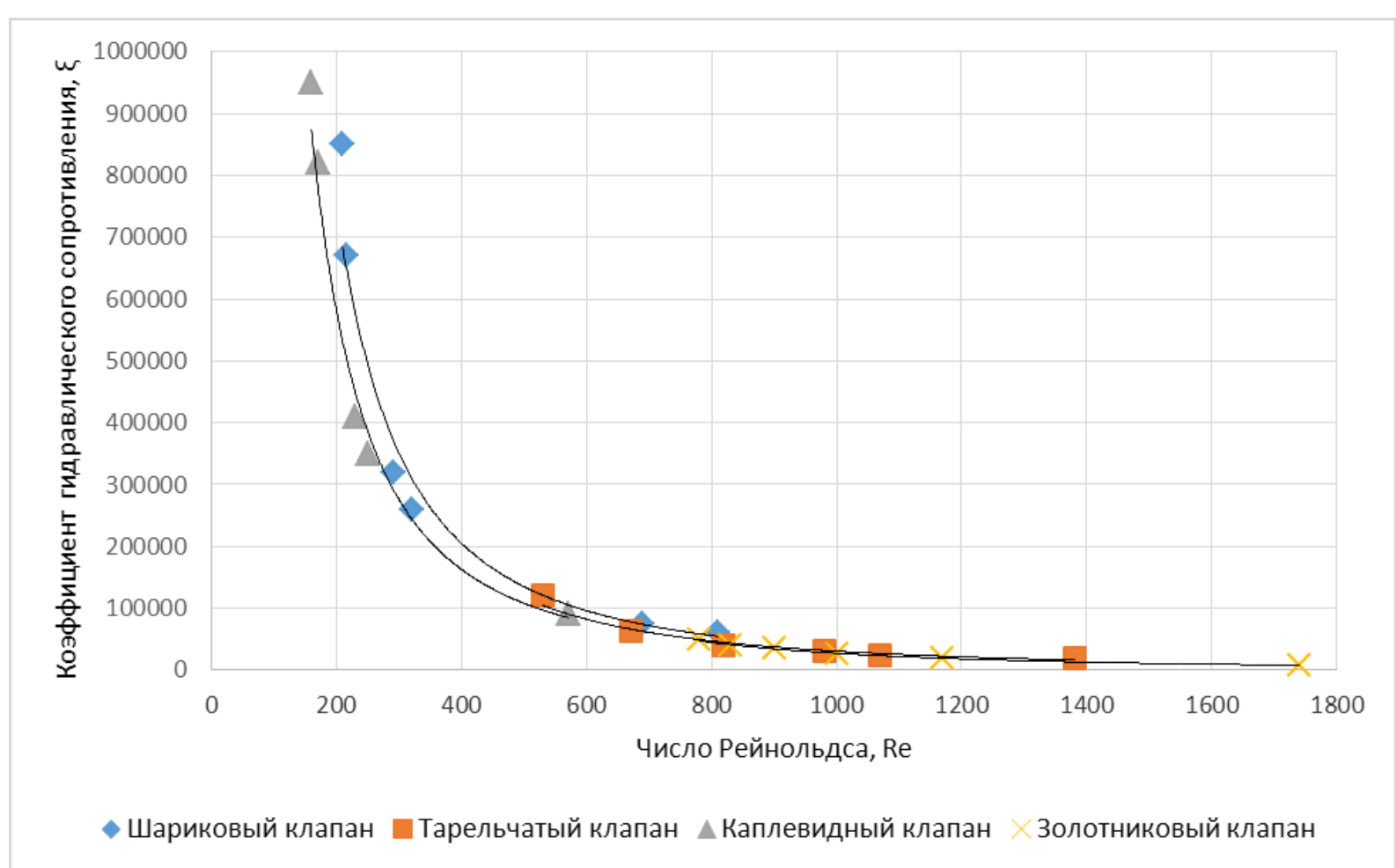

Рисунок 5. Результаты численного моделирования изменений значения коэффициента гидравлического сопротивления $\xi$ от числа Рейнольдса Re

Из анализа результатов проведенного литературного обзора и патентных исследований клапанных пар буровых поршневых насосов следует, что проблема повышения их надежности является актуальной, так как их долговечность не отвечает в достаточной мере современным требованиям.

\section{Выводы}

1. Основной причиной отказов клапанных пар буровых поршневых насосов является малая наработка на отказ (около 100 ч).

2. Основными причинами отказов клапанных пар буровых поршневых насосов являются:

- абразивное изнашивание, интенсифицирующееся в условиях высоконапорного воздействия промывочной жидкости, содержащей абразивные частицы; 
- ударный режим работы клапанных пар, интенсифицирующий износ их взаимно контактирующих уплотнительных поверхностей (тарели, седла, уплотнительных элементов);

- отклонения геометрических размеров, формы, расположения и биения поверхностей деталей и узлов клапанной пары;

3. Основными направлениями совершенствования конструкций клапанных пар с целью повышения их надежности и износостойкости являются:

- повышение износостойкости рабочих контактных поверхностей клапанных пар, использование для их изготовления современных износо- и коррозионностойких материалов;

- снижение уровня динамических нагрузок, действующих на клапанную пару при работе бурового насоса, их демпфирование;

- улучшение параметров гидравлического совершенства и конструктивного исполнения контактной пары «тарель - седло» с целью повышения надежности герметизации этой пары;

- совершенствование конструкции клапанной пары по результатам уточнений режима его работы на основе результатов компьютерного моделирования.

\section{Список используемых источников}

1. Абдюкова Р.Я. Анализ причин отказов клапанов буровых насосов // Проблемы сбора, подготовки и транспорта нефти и нефтепродуктов. 2012. Вып. 4. С. 65-70.

2. Бабаев С.Г. Основы теории надежности нефтепромыслового оборудования. Баку: Изд-во АГНА, 2015. 400 с.

3. Харисов М.И., Забиров Ф.Ш. Совершенствование конструкции клапанной пары бурового насоса // 69-я науч.-тех. конф. студентов, аспирантов и молодых ученых: сб. матер. докл. Уфа: Изд-во УГНТУ, 2018. 249 c. 
4. Абдюкова Р.Я. Виброизоляция седла клапана бурового насоса // Нефтегазовое дело. 2011. № 5. С. 243-253.

5. Литвинов В.M. Повышение надежности нефтепромысловых насосов. М.: Недра, 1978. 191 с.

6. Николич А.С. Поршневые буровые насосы. М.: Недра, 1973. 224 с.

7. Харисов М.И., Забиров Ф.Ш. Исследование способов и методов повышения надежности клапанной пары бурового насоса // Современные технологии в нефтегазовом деле - 2018: сб. тр. Междунар. науч.-техн. конф. в 2 т. Уфа: Изд-во УГНТУ, 2018. Т. 2. С. 126-127.

8. Абдюкова Р.Я. Новая конструкция клапана бурового // Проблемы сбора, подготовки и транспорта нефти и нефтепродуктов. 2012. Вып. 4. C. 34-39.

9. А.c. 672421 СССР, МКИ F 16 K 15/02, F 04 В 21/02. Узел клапана / Н.П. Уманчик, А.Б. Гулев, В.П. Ерошкин, И.Н. Макивоз, Г.М. Сорокин, К.И. Хазаржан. 2495549/25-08, Заявлено 07.06.1977; Опубл. 05.07.1979. Бюл. 25.

10. А.c. 1617231 СССР, МКИ F 16 К 15/02. Клапан / А.Б. Гуляев, Ю.М. Авилкин. 672421, Заявлено 28.09.1987; Опубл. 30.12.1990. Бюл. № 48 .

11. Пат. 117553 РФ, МПК F16K15/06, F16K1/36. Клапан бурового насоса / Д.О. Макушкин, А.Ф. Мурашко, А.В. Давыдов. 5894585/73-21, Заявлено 19.03.2007; Опубл. 20.03.2008. Бюл. 43.

12. Пат. 41825 Российская Федерация, МПК F 16 K 15/02. Клапан бурового насоса / Б.З. Султанов, Р.Я. Абдюкова, М.С. Габдрахимов. 4389076/22-79, Заявлено 14.06.2007; Опубл. 25.12.2010. Бюл. 56.

13. Пат. 1203299 РФ, МПК F 16 К 15/02. Клапанное устройство / Г.Ш. Плыкин. 5894536/73-11, Заявлено 09.11.2000; Опубл. 25.12.2001. Бюл. 44. 
14. Пат. 218079 РФ, МПК F 04 В 53/10, F 16 К 15/02. Клапанное устройство / Б.С. Захаров, И.Б. Захаров. 5894585/73-11, Заявлено 19.03.2001; Опубл. 20.03.2002. Бюл. 43.

15. А.c. 1830122 СССР, МКИ F 16 K 15/10. Клапан бурового насоса / Ю.А. Курников, И.Ф. Концур, А.В. Паневник, В.П. Здрок, Б.А. Бортник. 4856841/29, Заявлено 03.08.1990; Опубл. 23.07.1993. Бюл. 27.

16. Пат. 2073808 РФ, МПК F16К1/36. Клапанное устройство / Л.С. Айрапетов 5894536/73-11. Заявлено 12.07.1993; Опубл. 20.02.1997. Бюл. 43.

17. Пат. 2223435 РФ, МПК F 16 К 15/02. Клапанное устройство / Ю.М. Орлов, А.А. Климов, В.Б. Сюзев. 2002101639/06, Заявлено 15.01.2002; Опубл. 10.02.2004. Бюл. 44.

18. Долов Т.Р. Исследование работы клапанных узлов скважинных штанговых насосных установок: дис. ... канд. техн. наук. М., 2017. 154 с.

\section{References}

1. Abdyukova R.Ya. Analiz prichin otkazov klapanov burovykh nasosov [The Analysis of Drilling Pump Clack Valves Failures]. Problemy sbora, podgotovki i transporta nefti i nefteproduktov - Problems of Gathering, Treatment and Transportation of Oil and Oil Products, 2012, Issue 4, pp. 65-70. [in Russian].

2. Babaev S.G. Osnovy teorii nadezhnosti neftepromyslovogo oborudovaniya [Fundamentals of The Theory of Reliability of Oilfield Equipment]. Baku, AGNA Publishing House, 2015. 400 p. [in Russian].

3. Kharisov M.I., Zabirov F.Sh. Sovershenstvovanie konstruktsii klapannoi pary burovogo nasosa [Improving the Design of the Valve Pair of the Drilling Pump]. Sbornik materialov 69-oi nauchno-tekhnicheskoi konferentsii studentov, aspirantov i molodykh uchenykh [Proceedings of the 69th Scientific-Technical. Conference. Students, Graduate Students and Young Scientists]. Ufa, Publishing house USPTU, 2018. 249 p. [in Russian]. 
4. Abdyukova R.Ya. Vibroizolyatsiya sedla klapana burovogo nasosa [Vibration Insulation of the Valve Seat of a Mud Pump]. Neftegazovoe Delo Petroleum Engineering, 2011, No. 5, pp. 243-253. [in Russian].

5. Litvinov V.M. Povyshenie nadezhnosti neftepromyslovykh nasosov [Improving the Reliability of Oilfield Pumps]. Moscow, Nedra Publ., 1978. 191 p. [in Russian].

6. Nikolich A.S. Porshnevye burovye nasosy [Piston Drill Pumps]. Moscow, Nedra Publ., 1973. 224 p. [in Russian].

7. Kharisov M.I., Zabirov F.Sh. Issledovanie sposobov i metodov povysheniya nadezhnosti klapannoi pary burovogo nasosa [Investigation of Methods and Methods for Improving the Reliability of the Valve Pair of the Drilling Pump]. Sbornik trudov Mezhdunarodnoi nauchno-tekhnicheskoi konferentsii«Sovremennye tekhnologii v neftegazovom dele - 2018»: v 2 t. [Proceedings of the International Scientific and Technical Conference «Modern Technologies in Oil and Gas Business - 2018» in 2 vol.]. Ufa, USPTU Publ., 2018. Vol. 2, pp. 126-127. [in Russian].

8. Abdyukova R.Ya. Novaya konstruktsiya klapana burovogo [New Design of Valve Drilling]. Problemy sbora, podgotovki i transporta nefti i nefteproduktov - Problems of Gathering, Treatment and Transportation of Oil and Oil Products, 2012, Issue 4, pp. 34-39. [in Russian].

9. Umanchik N.P., Gulev A.B., Eroshkin V.P., Makivoz I.N., Sorokin G.M., Khazarzhan K.I. Uzel klapana [Valve Assembly]. Certificate of Authorship USSR, No. 2495549/25-08, 1979. [in Russian].

10. Gulyaev A.B., Avilkin Yu.M. Klapan [Valve]. A.C. 1617231 USSR, MKI F 16 K 15/02. Certificate of Authorship USSR, No. 672421, 1990. [in Russian].

11. Makushkin D.O., Murashko A.F., Davydov A.V. Klapan burovogo nasosa [Valve of a Mud Pump]. Patent RF, No. 117553, 2008. [in Russian].

12. Sultanov B.Z., Abdyukova R.Ya., Gabdrahimov M.S. Klapan burovogo nasosa [Valve of a Mud Pump]. Patent RF, No. 41825, 2007. [in Russian]. 
13. Plykin G.Sh. Klapannoe ustroistvo [Valve Device]. Patent RF, No. 1203299, 2001. [in Russian].

14. Zakharov B.S., Zakharov I.B. Klapannoe ustroistvo [Valve Device]. Patent RF, No. 218079, 2002. [in Russian].

15. Kurnikov Yu.A., Konzur I.F., Panevnik A.V., Zdrok V.P., Bortnik B.A. Klapan burovogo nasosa [Mud Pump Valve]. Certificate of Authorship USSR, No. 1830122, 1993. [in Russian].

16. Airapetov L.S. Klapannoe ustroistvo [Valve Device]. Patent RF, No. 2073808, 1997. [in Russian].

17. Orlov Yu.M., Klimov A.A., Syuzev V.B. Klapannoe ustroistvo [Valve Device]. Patent RF, No. 2223435, 2002. [in Russian].

18. Dolov T.R. Issledovanie raboty klapannykh uzlov skvazhinnykh shtangovykh nasosnykh ustanovok: dis. kand. tekhn. nauk. [Investigation of the Work of Valve Assemblies Downhole Sucker-Rod Pumping Units: Cand. Engin. Sci. Diss.]. Moscow, 2017. 154 p. [in Russian].

\section{Сведения об авторах}

\section{About the authors}

Харисов Марсель Илгизович, магистрант кафедры «Машины и оборудование нефтегазовых промыслов», УГНТУ, г. Уфа, Российская Федерация

Marsel I. Kharisov, Undergraduate Student of Machines and Equipment of Oil and Gas Fields Department, USPTU, Ufa, Russian Federation

e-mail: marselkharisov2009@yandex.ru

Забиров Фердинанд Шайхиевич, канд. техн. наук, доцент, профессор кафедры «Машины и оборудование нефтегазовых промыслов», УГНТУ, г. Уфа, Российская Федерация

Ferdinand Sh. Zabirov, Candidate of Engineering Sciences, Associated Professor, Professor of Machines and Equipment of Oil and Gas Fields Department, USPTU, Ufa, Russian Federation

e-mail: zabirov@ rusoil.net 